\title{
Formulation of a Remarkable Stylistic Approach: A Study Based on Ali Smith's Hotel World
}

\section{Hema S}

Postgraduate in English, N.S.S. College Ottapalam, Affiliated to University of Calicut, India

Received: 22 Sept 2020; Received in revised form: 11 Nov 2020; Accepted: 17 Nov 2020; Available online: 28 Nov 2020

(C)2020 The Author(s). Published by Infogain Publication. This is an open access article under the CC BY license (https://creativecommons.org/licenses/by/4.0/).

\begin{abstract}
Language employed by a writer has the potential to add literary qualities to a specific text. Language refers to the style that a writer, poet or playwright chooses to add more beauty and charm to the particular literary work. Ali Smith's style of writing determines the mood and feelings of the characters and the passage of time. The grammatical expressions that Smith employs in her novel give extra details related to the narratives and characters. This paper attempts to analyze how Ali Smith modifies the actual style of a traditional work by constructing a different kind of language in the novel Hotel World. The paper also explores the writer's subversion of normal conventions while highlighting language in the selected work.
\end{abstract}

Keywords - Language, narrative, postmodern, traditional, word.

\section{INTRODUCTION}

Ali Smith is regarded as one of the prominent contemporary literary figures in Scottish literature. Her works have reached the peak of success in the literary world. Hotel World has the main background as a hotel in an unnamed city, where the unexpected death of a young chambermaid, Sara happens. An abrupt creation of a group of strangers is the result of Sara's death. The strangers are namely the narrators of the novel and chance unites them together. As the novel begins, the main incident of the novel, i.e. Sara's death takes place and the section devoted to the depiction of this event is entitled as 'Past.' The ghost of Sara describes the cause of her death and the instance that results in her death. The ghost remains completely lost in a "purgatorial space" (Struncova 39).

Smith employs "internal rhymes, echoes, elisions and extended displays of verbal combinations like swirls of cake batter going through a blender" ("The Accidental"). Smith formulates a kind of writing where the novel concentrates more on the level of literary word games. Smith can also be regarded as tricky writer. The novel, to a larger extent is a ghost story where the ghost functions as an omniscient author. The narrative of the novel consists of the inner monologues of Sara and others whose lives intersect at the time when she died.

\section{STYLISTIC APPROACH IN ALI SMITH'S HOTEL WORLD}

The initial chapter 'Past' indicates the truth on how the "past events influence the present situation" (Navratilova 18). Smith shows how the past and present situation can be interconnected. The ghost of Sara moves aimlessly to derive attention. After Sara dies, her ghostly existence is literally "fading in and out of language", "I am hanging falling breaking between this word and the next" (Smith 31). The author breaks "the rules of grammar" intentionally (Struncova 39). "Fading" gives the possibility for "new significations" and it paves the way for new methods of "individual and cultural expressivity" (Struncova 39):

Remember you must live.

Remember you most love.

Remember you mist leaf.

(I will miss mist. I will mist leaf. I will miss the, the. What's the word? Lost, I've, the word. The word for. You know. 
I don't mean a room. I mean the way of the

.Dead to the .Out of this . Word (Smith 30-31).

The space that the writer provides in the above sentence represents the word 'world'. "The two signifiers word and world are separated by an irreducible gap" even though they are similar (Struncova 40). Readers observe a kind of "disintegration of language" and gaps in the narration (Struncova 40). "Language, existence and identity" are closely connected and it is represented through Sara's ghost escaping from the real world (Struncova 40). She also loses her fluency in speaking, "I climbed into the, the... I forget the word, it has it's own name" (Smith 6).

The third chapter of the novel is titled as 'present historic' and it is narrated in the third person narrative. The author switches from one kind of narration to other and thus, there is a mixing of different kinds of narration. The chapter mentions about Else, a young woman who is homeless. She is affected by tuberculosis and lives in the outskirts of an urban city.

Smith has used "defective language" in the case of Else (Struncova 41). The way in which she speaks is fragmented and it becomes difficult to understand. The words "Sprsmchn" means spare some change (63). Smith has included abbreviated forms of words in her writing to give more focus on language. In order to bring out the fact that the people who pass by completely reject Else, the author avoids usage of vowels. Therefore, the isolation experienced by Else is highlighted in language used by Smith.

The chapter 'Present historic' mainly describes the hopeless condition of woman. The character Else has no future, abandoned her past and present does not exist for her. It shows how the author has chosen a typical postmodernist character with no actual existence and it is reflected in the language of the work. The perspectives put forward by Else are associated to the past with narratives giving an idea of her life, which leads to the present situation. Language itself acts as a heavy "burden for Else" as she says that she likes poetry more than novels (Struncova 41).

The part 'future conditional' is also written by giving a postmodern attribute to the language. The events that have been mentioned in this section happen sometime in the future. It is narrated from the point of view of Lise, who "worked as a receptionist in the Global Hotel" before the death of Sara but she "no longer works in the hotel" after Sara's death (Struncova 41).
The plot of this chapter is concerned with "Lise's attempts to complete filling a form to overcome her illness" (Navratilova 20). A slip between the first and third person narrative and the combination of both these narrations shows that her mind is moreover disturbed. She is also alienated from the external world not only by the walls of her apartment but also by language. Lack of her identity is represented through lack of her potential to convey language. It becomes evident when she fails to describe herself while filling the form:

\section{About you-continued}

any part of it,

If you need help filling in this form, or

phone 0800882200

Tell us about yourself.

Well. I am a nice person.It was sometime in the future. Lise was lying in bed.That was practically all the story there was. (81)

Smith has provided certain blank spaces in between the lines to show that Lise has no words to express. "The narrative also transforms from past tense to present tense", thus following a "contradicting trajectory" and it signifies the "confusion" that Lise faces (Struncova 42-43). It also represents the sense of nothingness.

As far the section 'future conditional' is concerned, the author has not made any kind of difference between "speech and narrative" (McKay 99). Smith has not given importance to the traditional notion of placing 'speech' superior to 'narrative'. She has removed 'quotation marks' and hence speech and narrative becomes similar in the novel. The fact becomes clear in the following sentences of the novel:

Now again. The woman in the hotel uniform is saying something but Else is dizzy and can't hear properly. She looks at the woman's shoes. They are recent and fashionable; they have thick soles of the kind of moulded plastic that looks industrial and prehistoric at the same time $[. .$.$] The one that got away. Nearly.$ (62-63)

Smith employs "internalized first person narrative" in the novel and the reader has to depend on the lack of 'first person pronoun' to find out the person who narrates the plot (McKay 100).

As far as the section 'future in the past' is concerned, author has eliminated or removed punctuation 
marks at necessary positions to represent the disappointment of Clara and her struggle to accept her own sister's death. Clare Wilby, Sara's sister who recollects the past of Sara, narrates the section in first person narrative. The language changes from "grammatical into something more metaphorical" and from "analytical to poetic" (Struncova 44). The flow of words that appear metaphorically shows the tears that flow from the eyes of Clara. Hence, the "metaphorical" language employed by the author is associated to the emotions of the character and can be regarded as an important strategy adopted by the author.

Hotel World cannot be treated as a proper novel but it is a collection of entangled stories. Realistic features are attributed to characters. Sara's ghost is not depicted by Smith to develop fear in the minds of readers and the novel is not based on a real 'ghost story'. Sara's "fading words, Clare's heartbreaking monologue", breaks in narration, "word gaps in narration", etc. are also incorporated by the writer to give more focus on language and also the disruption of character's identities is projected through the "dissolution of language" (Struncova 46).

The concept of language stands for the process of moving away from the world. Penny's "flawless" use of language makes the readers understand the fact that she is concerned about her loneliness (Navratilova 33). Sara's ghost informs and explains her sensations and memories. Sara's ghost can be regarded as a proper character of the novel. The author uses transcription of a fatal sound in the beginning of the novel to indicate Sara's "mortal fall", "Woooooooo- hooooooo what a fall what a soar what a plummet what a dash into dark into light... what an end" (3). The word 'what' also gets repeated in the sentence to denote the final experiences of Sara. The fall is related to the "language construction, images and symbols" (Navratilova 21).

The chapter 'future conditional' has been presented in such a way that the paragraphs begin with the symbol ' $\&$ ' and the word since. Sentences have not been separated by full stops and thus, the conjunction \&'s meaning and connects the sentences:

$\&$ since the main thing is I counted I was there \& since I have come home with really the most fucking amazing new shoes \& also they gave me the breakfast $\&$ it was really good

$\&$ since there is the five pound note

\& since I knew I did know already about the horrible thing about being crammedin all upside down I had read it in the papers it wasn't a surprise or a shock or anything I did know (185)

This shows how Smith has tactfully played with language and conveys the fact that the modern world itself is disconnected and empty. Solutions are much less for problems like lack of identity and isolation. Lise is the central focus of this chapter and playfulness of language represents her continuous flow of thoughts.

The chapter entitled 'perfect' represents a reporter named Penny who has been accommodated in Hotel World to write down a review about it. As far as reporter is concerned, the facts that he or she reports appears to be a challenging story. Language never bounds Penny when compared to other characters of the novel. Each and every incident that takes place is translated by Penny. The title of this section also has an importance as Penny is indirectly connected to the concept of 'perfection'. This is shown through a different kind of style by the writer:

Fawless, Penny typed. She deleted the F and replaced it with an I. Then she put the $\mathrm{F}$ back on the front again...Damn, Penny said.

FFFFFFFFFFFFFFFFFFFFFFFFFFFFF FFFFFFFFFFFF

\section{FFFFFFFFFFFFFFFFFFFFFFFFFFFFF FFFFFFFFFFFFFFF \\ FFFFFFFFFFFFFFFFFFFFFFFFFFFFF FFFFFFFFFFFFFFF}

FFFFFFFFFFFFFFFFFFFFFlawless, the computer screen said. (125-126)

Penny uses certain adjectives to describe the hotel and its services. It becomes evident in the language that Smith employs. Penny understands the external world by a "distorted idealistic view" and also loses connection with the world around her (Struncova 44). The title given to the section corresponds to the work and the adjectives that are being used. The word perfect suggests smoothness and something, which is ultimately the best. The character Penny regards herself as a perfect individual. Hence, the selection of certain words contributes to a different version of language. The final section namely 'present' contains no plot and it gives a lyrical description of an autumn morning. The story is narrated by an unknown narrator and mentions that the elements of other world coexist with our reality. Garden is explained by the writer as, "There are little flies suspended in the air, new and reckless. The feverfew is green" (225).

Smith has structured the layout of the last pages of the novel as rather "playful" and makes the readers 
return to the very beginning of the novel (Navratilova 23). Playful paraphrases are included in a separate page by quoting from the work titled Memento Mori by Muriel Sparks. The font size of the final few words of the novel diminishes as if Sara's ghost is ultimately capable of leaving its body and the world. Seven pages of the novel are moreover blank and have not been numbered. Lack of language is suggested through empty pages. It shows the emptiness that surrounds the characters and allows the readers to interpret the novel in their own ways.

Robert Crawford observes the experimental way of writing that Smith adopts:

Hotel World marks a stylistic advance in Smith's fiction that is as striking as the stylistic discoveries made in prose by James Kelman two decades earlier. Like Kelman's, Smith's breakthrough appears technically simple, but has led to profound consequences. (McKay 102)

A skillful and truthful representation is given to Clare's understanding of reality in the novel. The pages written by Clare mainly follow a diary-writing format; there is no paragraph division and the content is devoid of punctuation marks. The symbol or sign that is used in these pages is ' $\&$ '. It denotes "connecting words, question and exclamation marks" (Navratilova 31). Smith also includes "devices like frequent repetition, leaving out words, putting words together", etc. along with the addition of "symbols or signs" (Navratilova 31). Such elements are added to the text in order to bring out the problems that Clare is compelled to encounter, "It's been ClareWilby'ssister

didherselfinclarewilby'ssisterdidherselfin those fickingwankheads at the north gate shouting it when I went past on the other side of the road \& now I know she didn't" (194).

Thus, Smith has made the text really fragmented in nature by employing a new style of writing and this helps readers understand the role of language. Smith's treatment of language often breaks conventional forms of writing and thus creates a new form of writing.

The writer also includes a re-adaptation of a quotation in the book Memento Mori written by Muriel Sparks. The quotation from the work is "Remember you must live" (Verongos). Smith reconstructs this particular quotation in her own ways by giving "postmodern playfulness" (Navratilova 24). She writes, "Remember you must live. Remember you most love. Remember you mist leaf" (30). In Memento Mori, a mysterious phone call is received by a close circle of friends with a simple message as "remember, you must die" (Navratilova 24).

Certain sentences in the novel are shortened and brackets are used. The main aim of this concept is to show the "fragmentation" of the speech made by the character (Navratilova). Else's dialogues are mainly abbreviated forms of sentences since she is very much affected by illness and it becomes too difficult for her to speak. She feels that she is not needed for this world and this emotion is suggested in the novel, "(Cn y sprsmchn? Thnk y)" (36).

The writer enables the readers to find out their own conclusions for the novel. Smith employs narrative strategies like "fragmentation, temporal distortion, puns, blank pages, internal texts, tension between complete and incomplete sequences", etc. to develop unexceptional narratives that focus not only on the characters but enable decline of social values (Navratilova).

\section{CRITICAL OPINIONS ON THE NOVEL}

Hotel World has been positively approached by the reading public and literary world. Jeanette Winterson, in an endorsement on the back cover of Ali Smith's Hotel World, comments that "Ali Smith has got style, ideas and punch. Read her." Sunday Times, in an endorsement on the back cover of Ali Smith's Hotel World, comes forward with the opinion that "Smith's powerful prose transforms these half- lives into miniature epiphanies, subtly working them together into a whole that is full of gaps and puzzles, but never lacking in warmth or humour... a rewarding read."

\section{CONCLUSION}

According to Smith, "Language and fiction give us how we could be, how we can be, if there's a realization of other words, voices, structures. You just have to keep yourself open: all our selves" ("Interviewed" 75). As far as the first section of the novel is concerned, Smith follows the tone of the postmodern playwright Samuel Beckett. She has adopted different styles and creates her own voice. However, Smith does not follow a mere imitation. According to the thoughts of characters, style changes from one character to another. She also includes literary borrowing and humour in the novel. Thus, by employing non-conventional language, the novel becomes significant with a complete postmodern outlook.

Readers have the doubt whether it is Sara or the ghost that is speaking. The novel cannot be read in an easy manner. Like most postmodern works, the language of the novel creates a kind of confusion. Moreover, Smith's 
novels are unique in its own way and create a huge and powerful impact on the reader's conscience. Therefore, Smith's contribution to literature is not to break the essence of traditional novels but to discover a kind of writing that has substance. Hence, Smith suppresses the conventional modes of writing and gives birth to a postmodern form of writing.

\section{REFERENCES}

[1] Armitstead, Claire. (2015). All there is an Interview about the Short Story. academia edu. Retrieved from www.academia.edu/8207753/.

[2] Burianova P. (2016, May). Questioning Gender through the Test of History, pp. 7-90. Retrieved from is.cuni.cz/webapps/zzp/download/120226505.

[3] Connor, Steven, editor. (2004). The Cambridge Companion to Postmodernism. $1^{\text {st }}$ ed., Cambridge University Press, pp. 3-50.

[4] Farrell, Maggie O. (2001). Cover endorsement. Hotel World, by Ali Smith, Penguin Books.

[5] Gezels H. (2016). Full Manuscript. Ghent University Library. Retrieved from lib.ugent.be/fulltxt/RUG01/002/349/247/RUG01002349247_2017_0001_AC.pdf.

[6] Interviewed by Caroline Smith. (2007). GALA, pp. 75-79. Retrieved from gala.gre.ac.uk/4924/1/ali_smith.pdf.

[7] Introduction to Postmodernism. University of Pugent Sound, pp. 1-4. Retrieved from www2.ups.edu/faculty/velez/Span_301/html/supple/pomo. DOC.

[8] McKay, John. (2008). The Banal Daily Drudge: Telling Stories in Scotland. eSharp, Spinning Scotland: Exploring Literary and Cultural Perspectives, pp. 97-108. www.gla.ac,uk/esharp.

[9] Navratilova, Pavla. (2009). Postmodernist Features in Ali Smith's Novels. IS MU, pp. 5-58. is.muni.cz/th/r22ta/postmodernistfeatures.pdf.

[10] Platt, Len. (2015). Postmodern Literature and Race. Google Books, p. 42. Retrieved from books.google.co.in/books?id.

[11] Smith, Ali. (2001). Hotel World. Penguin Books.

[12] ---,. The Accidental. (2005). Penguin Books.

[13] Struncova, Katerina. (2013). Love, Alienation and Identity in Ali Smith's Novels. ISMU, pp. 25-38. is.muni.cz/th/ryjsb/dp_-_ali_smith.pdf.

[14] The Accidental. Wikipedia. Retrieved from en.wikipedia.org/wiki/The_Accidental.

[15] Verongos, Helen T. (2006, April 16). Muriel Spark, Novelist Who Wrote The Prime of Miss Jean Brodie, Dies at 88. The New York Times. Retrieved from www.nytimes.com/2006/04/16/world/16spark.html.

[16] Vesterinen, Noora. (2014). Secrets and ethics in Ali Smth's The Accidental. Semantic Scholar. Pdfs.semanticscholar.org/57df/d97cf896c2a6a2d6c8413dfb 5250fb759eef.pdf.
[17] Washington Post. (2001). Cover endorsement. Hotel World, by Ali Smith, Penguin Books.

[18] Woods, Tim. (1999). Beginning Postmodernism. Manchester University Press, pp. 1-66. 